\title{
Difficult asthma: Consider all of the possibilities
}

\author{
Lisa C Cicutto PhD ACNP CAE ${ }^{1,2,5}$, Kenneth R Chapman MD FRCPC ${ }^{2,4,5}$, \\ Dean Chamberlain $\mathrm{MD}^{3,4,5}$, Gregory P Downey MD FRCPC ${ }^{2,4,5}$ \\ ${ }^{1}$ Faculty of Nursing and ${ }^{2}$ Division of Respirology, Department of Medicine, and ${ }^{3}$ Department of \\ Pathobiology and Laboratory Medicine, ${ }^{4}$ Faculty of Medicine, University of Toronto, and \\ ${ }^{5}$ the Toronto General and Western Hospitals of the University Health Network, Toronto, Ontario
}

LC Cicutto, KR Chapman, D Chamberlain, GP Downey. Difficult asthma: Consider all of the possibilities. Can Respir J 2000;7(5):415-418.

Asthma is a common respiratory disease that can often be managed successfully. However, there are patients that do not respond to the maximum doses of standard therapy and subsequently have a reduced quality of life. Many factors can contribute to a failure to respond to treatment, and a comprehensive approach is important when assessing and evaluating these patients. This report describes a patient referred for 'difficult to control asthma' who had multiple emergency department visits and hospitalizations. In addition to a history of wheezing, spirometry showed impaired flow and vital capacity was reduced. Further investigation showed a normal total lung capacity, and a computed tomography scan revealed main bronchus blockage by a tumour, which was confirmed by bronchoscopy. This led to a surgical resection of a mucoepidermoid carcinoma. This case highlights the need to consider all possibilities during the evaluation of patients with difficult asthma.

\section{Asthme rebelle : avez-vous envisagé toutes les possibilités?}

RÉSUMÉ : L'asthme est une maladie respiratoire fréquente qui se traite généralement bien. Cependant, certains patients ne réagissent pas aux doses maximales de traitement usuel et voient leur qualité de vie diminuée. Beaucoup de facteurs peuvent expliquer l'échec du traitement et il faut adopter une approche globale lorsque vient le temps d'évaluer ces patients. Voici le cas d'un patient dirigé vers un spécialiste pour asthme rebelle; il s'est présenté souvent à l'urgence et a été hospitalisé à plusieurs reprises. Outre les antécédents de wheezing, la spirométrie révèle une diminution du débit expiratoire et de la capacité vitale. Des examens plus poussés font état d'une capacité pulmonaire totale normale, mais une tomodensitométrie montre la présence d'une tumeur qui obstrue la bronche souche; son existence a été confirmée par une bronchoscopie. Il y a eu résection chirurgicale d'un carcinome muco-épidermoïde. Le présent cas illustre très bien la nécessité d'envisager toutes les possibilités dans le cadre de l'évaluation des patients souffrant d'asthme rebelle.

Key Words: Difficult asthma; Mucoepidermoid carcinoma

$\mathrm{M}$ ost patients with asthma are easily diagnosed and respond to standard therapy that includes short acting inhaled beta2-agonists as needed for symptom control and maintenance treatment with inhaled corticosteroids. However, approximately $5 \%$ of patients do not respond to this treatment approach and, thus, require additional investigation to determine the reason for this failure. Difficult asthma is often defined as a failure to achieve control with the maximum recommended doses of inhaled therapy (1). Several factors may contribute to a poor response to standard therapy, and it is important to consider these in a systematic fashion to identify those that are relevant to the particular patient. Questions that should be addressed under these circumstances include: does the patient definitely have asthma or is there alternative pathology masquerading as asthma; are medications being delivered to the lungs at appropriate doses (including issues 
TABLE 1

Pulmonary function testing before and after the administration of a bronchodilator (BD) in a patient with suspected difficult to treat asthma

\begin{tabular}{|c|c|c|c|c|c|c|}
\hline \multirow[b]{2}{*}{ Pulmonary function test } & \multicolumn{3}{|c|}{ September 1997} & \multicolumn{3}{|c|}{ August 1998} \\
\hline & Pre BD (L) & $\%$ predicted & Post BD (L) & Pre BD (L) & $\%$ predicted & Post BD (L) \\
\hline Forced vital capacity (FVC) & 2.16 & 62 & 2.54 & 2.25 & 65 & 2.22 \\
\hline Forced expiratory volume in $1 \mathrm{~s}\left(\mathrm{FEV}_{1}\right)$ & 1.64 & 55 & 1.91 & 1.61 & 54 & 1.56 \\
\hline $\mathrm{FEV}_{1} / \mathrm{FVC}(\%)$ & 76 & 89 & 76 & 83 & 102 & 82 \\
\hline $\mathrm{FEF}_{50}$ & 2.44 & 70 & 2.29 & 2.03 & 58 & 2.52 \\
\hline Total lung capacity (TLC) & & & & 4.48 & 91 & \\
\hline RV/TLC (\%) & & & & 49 & 166 & \\
\hline Carbon monoxide diffusing capacity of the lungs & & & & 18.44 & 97 & \\
\hline
\end{tabular}

FEF 50 Forced expiratory flow after $50 \%$ of vital capacity has been expelled

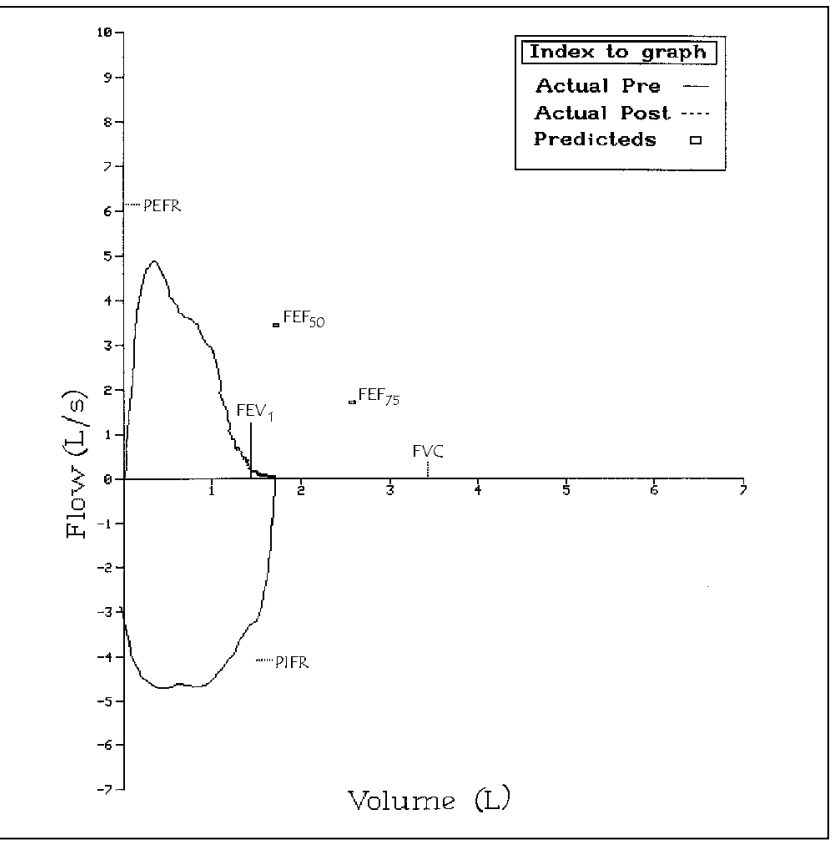

Figure 1) A flow volume loop demonstrating no evidence of extrathoracic obstruction. FEF50/75 Forced expiratory flow after $50 \% / 75 \%$ of vital capacity has been expelled; FEV $V_{1}$ Forced expiratory volume in $1 \mathrm{~s}$; FVC Forced vital capacity; PEFR Peak expiratory flow rate; PIFR Peak inspiratory flow rate

of proper use of delivery devices and compliance); are there unidentified exacerbating triggers in the environment; are there potential aggravating factors or comorbidities (eg, smoking, chronic obstructive pulmonary disease, cardiac disease); and has the patient followed a strict treatment plan for six months or more? $(1,2)$. This paper presents and discusses a case referred for control of difficult asthma to illustrate the importance of this systematic approach to a patient with ostensible asthma.

\section{CASE PRESENTATION}

A 35-year-old female presented with a history of cough, wheezing and dyspnea of four years' duration. She was born in Sri Lanka, grew up in England and immigrated to Canada at age 35 years. She had no history of respiratory problems, including asthma, as a child. She did have a history of eczema as a child that resolved spontaneously. She had a seven pack-year smoking history but had stopped smoking five years previously. Four years before her first visit to the Asthma Centre at the Toronto Western Hospital, she developed intermittent episodes of dyspnea, wheezing and cough after an upper respiratory tract infection. She was evaluated by her family physician, and a presumptive diagnosis of asthma was made, but no spirometry was obtained. Treatment with an inhaled beta2-agonist was instituted, giving partial relief of her symptoms. Two years before her visit, she was evaluated by an ear, nose and throat surgeon because of postnasal drip and sinusitis. No polyps were seen on rhinoscopic examination, and the patient underwent septal rhinoplasty. The episodes of dyspnea become more frequent and of longer duration. In the year preceding her evaluation, the dyspnea and wheezing became continuous. Treatment with high dose, inhaled corticosteroids (fluticasone $1000 \mu \mathrm{g} / \mathrm{day}$ ), zafirlukast, theophylline and salmeterol did not improve her symptoms. Throughout the preceding year, she made multiple visits to the emergency department, some with subsequent hospitalization. During this time, she was assessed by several specialists including respirologists. Spirometry demonstrated mixed defect, with a combination of reduced vital capacity and mild airflow limitation with improvement after bronchodilator (Table 1). She was given several courses of oral corticosteroids (50 mg prednisone/day for two to three weeks) with a minimal improvement in symptoms. Two months before her initial evaluation, she was admitted to a community hospital for an asthma exacerbation, and received treatment with intravenous methylprednisolone and antibiotics but did not resolve her symptoms. At this time, she was referred to the Asthma Centre at the Toronto Western Hospital for the further evaluation of asthma that was considered to be difficult to control.

Physical examination revealed a woman in no respiratory distress. Abnormal findings included inspiratory and expiratory wheezes that were heard diffusely but were loudest over the central airways.

The initial differential diagnoses included steroid-resistant asthma, allergic bronchopulmonary aspergillosis, vocal cord 


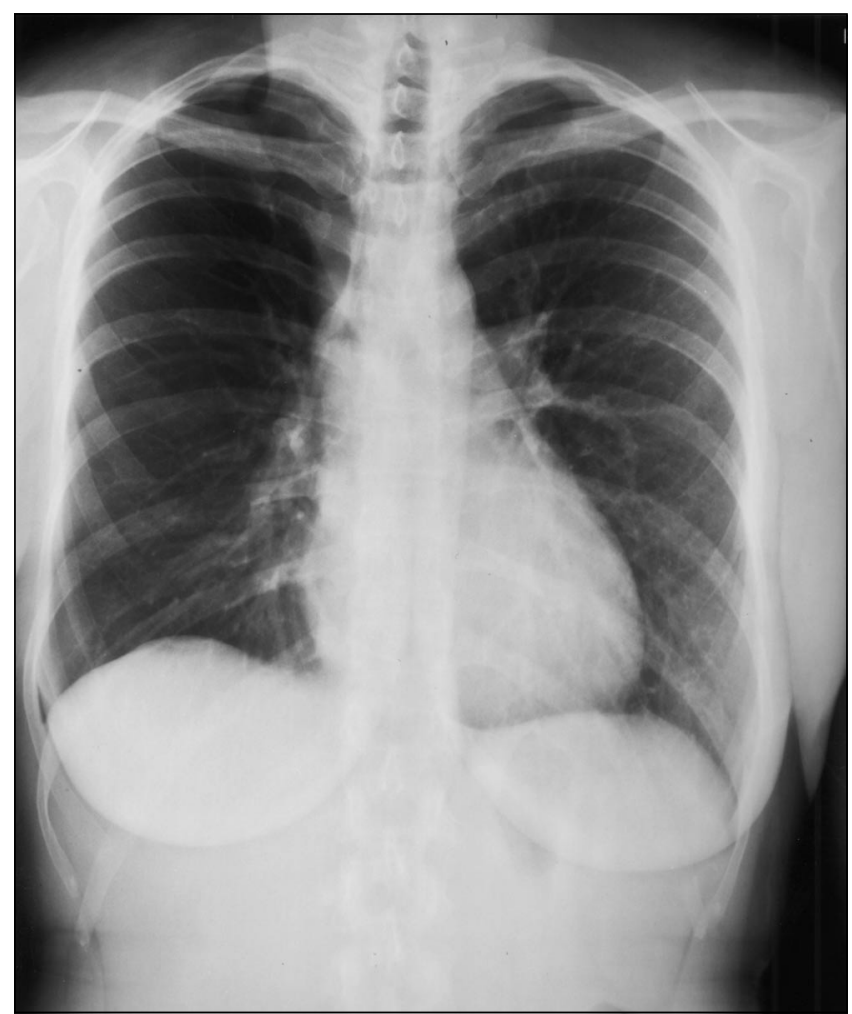

Figure 2) Posterior-anterior chest radiograph of the patient at the time of initial evaluation. Note the absence of the air column in the right main stem bronchus

dysfunction, subglottic stenosis and other types of large airway obstruction, such as a foreign body or tumour in the central airways. Pulmonary function testing demonstrated a reduced vital capacity with evidence of gas trapping. There was no improvement after bronchodilator administration (Table 1). A flow volume loop demonstrated no evidence of extrathoracic obstruction (Figure 1). During subsequent visits, additional diagnostic studies were performed. Methacholine testing was negative but inspiratory stridor was noted during the test. There was no blood or sputum eosinophilia. Direct laryngoscopy demonstrated no evidence of vocal cord dysfunction or subglottic stenosis. A chest X-ray (Figure 2) revealed a filling defect in the right main stem bronchus extending into the proximal trachea. A computed tomography scan demonstrated the presence of an intrabronchial mass (Figure 3). During evaluation she developed acute dyspnea, and physical examination demonstrated tracheal deviation to the right, markedly diminished movement of the right hemithorax and diminished breath sounds on that side compatible with atelectasis of the right lung. Ventilation perfusion lung scanning revealed markedly diminished ventilation and perfusion to the right hemithorax. Urgent rigid bronchoscopy demonstrated a tumour completely occluding the right main stem bronchus extending into the proximal trachea.

The working diagnosis was a bronchial tumour, most likely a carcinoid. The patient underwent a right pneumonectomy with a sleeve resection of the trachea. The final pathological diagnosis was mucoepidermoid carcinoma of intermediate

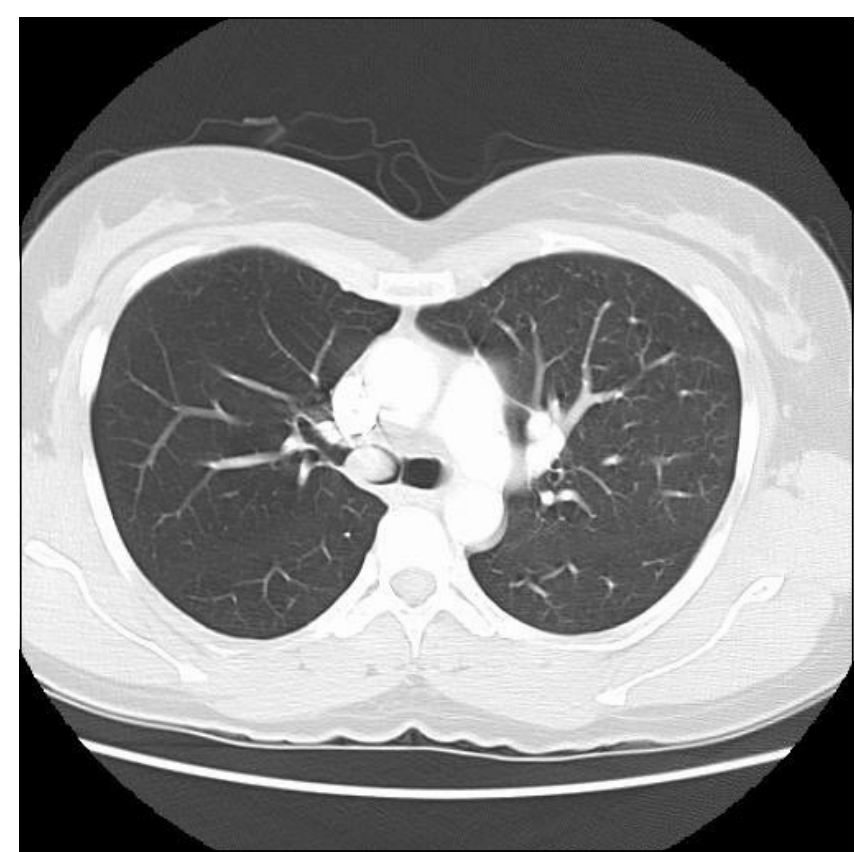

Figure 3) Computed tomography scan of the chest, demonstrating a mass in the right main stem bronchus

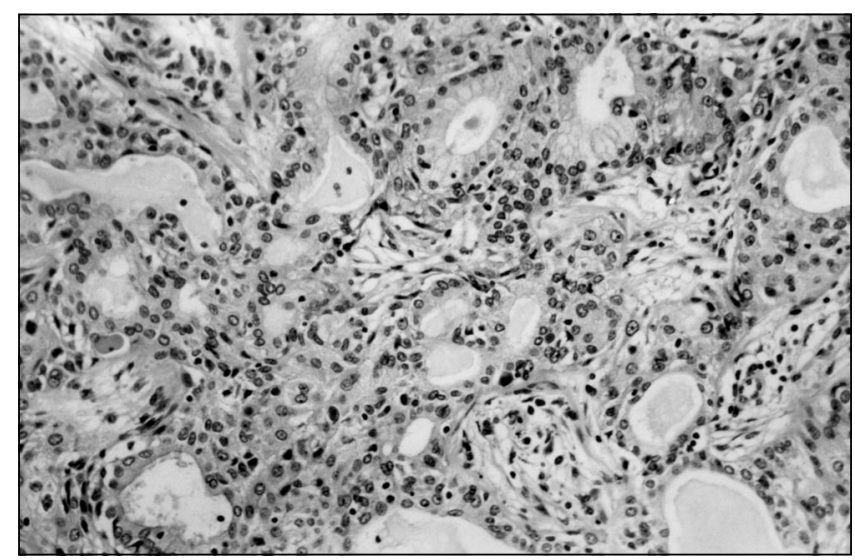

Figure 4) Bronchial tumour showing glandular differentiation admixed with a background of 'intermediate cells' typical of mucoepidermoid carcinoma. Other fields demonstrated more epidermoid features (not illustrated). (Hematoxylin and eosin stain, original magnification $\times 160$ )

grade with spread to one of three interlobar lymph nodes (Figure 4). The final staging was as follows: T3 (tumour diameter greater than $5 \mathrm{~cm}$ ), N1 (ipsilateral node involvement), M0 (no evident metastases). The patient improved dramatically after the surgery and has remained disease free at year one of follow-up.

\section{DISCUSSION}

This woman had evidence of reversible airflow limitation consistent with asthma early in the course of her disease. However, the primary basis for her refractory symptoms was not difficult asthma but rather an endobronchial tumour obstructing a major airway. This case illustrates the importance of a comprehensive approach to the evaluation of such patients. The evaluation at our centre yielded observations that 
TABLE 2

\section{Potential causes of upper airway obstruction}

Vocal cord dysfunction
Tracheomalacia
Subglottic stenosis (post intubation, Wegeners granulomatosis,
idiopathic)
Foreign body (food particle, dental material)
Endobronchial tumour (bronchogenic carcinoma, carcinoid,
mucoepidermoid carcinona)
Thyroid enlargement (carcinona, goiter)
Vascular compression (right-sided aortic arch, aortic aneurysm)

were inconsistent with a diagnosis of 'difficult' asthma. First, physical examination demonstrated both inspiratory and expiratory wheezes that were loudest over the central airways. Second, pulmonary function testing revealed a reduced vital capacity and gas trapping without evidence of significant reversible airflow limitation. In retrospect, the gas trapping was likely due to a check valve effect of the endobronchial tumour, with complete occlusion on expiration. Finally, the lack of blood and sputum eosinophilia were atypical of asthma $(3,4)$, although a lack of sputum eosinophilia in asthmatics may predict a lack of benefit to corticosteroids (5).

It is important to consider alternative diagnoses when assessing patients labelled as having 'difficult to manage asthma'. Chronic obstructive pulmonary disease may present with certain features of asthma, and there is often substantial overlap between these conditions. Against this diagnosis were the patient's age, her minimal smoking history and the restrictive pattern on pulmonary function testing. Another possibility is vocal cord dysfunction; patients with this syndrome exhibit episodic wheezing and dyspnea as a result of paradoxical laryngeal adduction during both inspiration and expiration. This upper airway phenomenon can mimic classical asthma, and may result in multiple emergency department visits, hospitalizations and even intubations. It is often associated with multiple diseases or psychological disturbances, and the diagnosis is notoriously difficult to confirm (6). Individuals with vocal cord dysfunction often have an inability to perform spirometric tests reproducibly, which suggests a problem of upper airway closure (2). The gold standard for diagnosis is laryngoscopy during an acute episode, either spontaneous or induced, demonstrating inappropriate vocal cord motion with adduction of the vocal cords on inspiration or expiration with a small anterior 'chink' remaining for airflow.

With respect to this patient, data suggestive of the diagnosis of vocal cord dysfunction included the referring diagnosis of difficult to treat asthma, multiple emergency department visits and hospitalizations, wheezing and dyspnea unresponsive to bronchodilators and steroids, and wheezing on inspiration (stridor) and expiration heard loudest over the central airways. However, direct laryngoscopic examination did not support this diagnosis.

Upper airway obstruction due to diverse causes can present with features that mimic certain aspects of asthma (Table 2). Many of these obstructions are potentially life threatening but eminently treatable if recognized early. Neoplasms of the upper airway, while less common, are clearly an important consideration in patients with features atypical of asthma. Bronchogenic or metastatic (eg, breast, renal cell carcinoma, melanoma) carcinomas are the most frequent. Carcinoid tumours, although less common, tend to be less aggressive and are often amenable to complete resection.

Mucoepidermoid carcinoma of the tracheobronchial tree, a rare tumour comprising only $0.1 \%$ to $0.2 \%$ of primary lung malignancies, is thought to originate from the minor salivary glands lining the tracheobronchial tree (7-12). Prominent symptoms experienced by these patients include cough, hemoptysis, wheezing, dyspnea and chest pain $(7,13,14)$. However, patients may also be asymptomatic $(13,14)$. Possible radiographic abnormalities include a solitary nodule or a mass, with or without findings of postobstructive pneumonia or atelectasis $(7,12,14)$. The tumour usually appears as a sharply marginated or lobulated airway mass on computed tomography scans (14), although it may adapt to the branching features of the airways. Treatment primarily involves surgical resection, if possible, and, occasionally, chemotherapy and/or radiation $(7-9,15)$.

\section{CONCLUSIONS}

Although this case presented with some clinical features suggestive of asthma, several features on physical examination and laboratory testing were not consistent with this diagnosis. When patients do not respond to conventional therapy, it is important to keep an open mind and consider all the possibilities to avoid misdiagnosis and delays in appropriate treatment.

\section{REFERENCES}

1. Barnes PJ, Woolcock AJ. Difficult asthma. Eur Respir J 1998;12:1209-18.

2. Thomas PS, Geddes DM, Barnes PJ. Pseudo-steroid resistant asthma. Thorax 1999;54:352-6.

3. Jeffery PK. Differences and similarities between chronic obstructive pulmonary disease and asthma. Clin Exp Allergy 1999;29(Suppl 2):14-26.

4. Hargreave FE, Pizzichini E, Pizzichini MMM. Assessment of airway inflammation. In: Barnes PJ, Grunstein M, Leff A, Woolcock A, eds. Asthma, vol 2. Philadelphia: Lippincott-Raven, 1997:1422-50.

5. Pavord ID, Brightling CE, Woltmann G, Wardlaw AJ. Non-eosinophilic corticosteroid unresponsive asthma. Lancet 1999;353:2213-4.

6. Newman KB, Mason UG III, Schmaling KB. Clinical features of vocal cord dysfunction. Am J Respir Crit Care Med 1995;152:1382-6.

7. Leonardi HK, Jung-Legg Y, Legg MA, Neptune WB. Tracheobronchial mucoepidermoid carcinoma: Clinicopathological features and results of treatment. J Thorac Cardiovasc Surg 1978;76:431-8.

8. Miller DL, Allen MS. Rare pulmonary neoplasms. Mayo Clin Proc 1993;68:492-8.

9. Shimizu J, Watanabe Y, Oda M, Morita K, Tsunezuka Y, Nonomura A. Clinicopathologic study of mucoepidermoid carcinoma of the lung. Int Surg 1998;83:1-3.

10. Heitmiller RF, Mathisen DJ, Ferry JA, Mark EJ, Grillo HC. Mucoepidermoid lung tumors. Ann Thorac Surg 1989;47:394-9.

11. Turnbull AD, Huvos AG, Goodner JT, Foote FW Jr. Mucoepidermoid tumors of bronchial glands. Cancer 1971;28:539-44.

12. Yousem SA, Hochholzer L. Mucoepidermoid tumors of the lung. Cancer 1987;60:1346-52.

13. Hause DW, Harvey JC. Endobronchial carcinoid and mucoepidermoid carcinoma in children. J Surg Oncol 1991;46:270-2.

14. Kim TS, Lee KS, Han J, et al. Mucoepidermoid carcinoma of the tracheobronchial tree: Radiographic and CT findings in 12 patients. Radiology 1999;212:643-8.

15. Cerfolio RJ, Deschamps C, Allen MS, Trastek VF, Pairolero PC. Mainstem bronchial sleeve resection with pulmonary preservation. Ann Thorac Surg 1996;61:1458-63. 


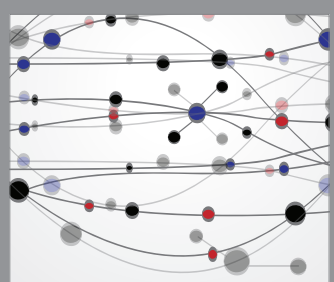

The Scientific World Journal
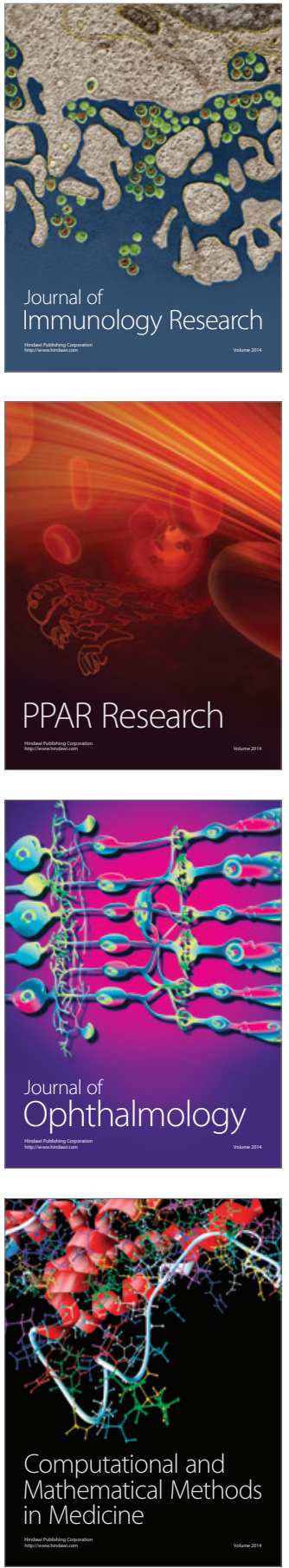

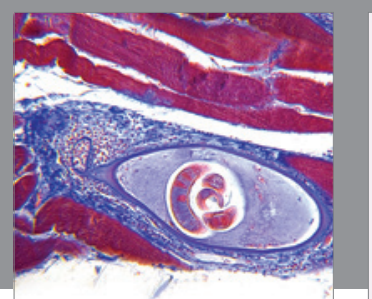

Gastroenterology Research and Practice

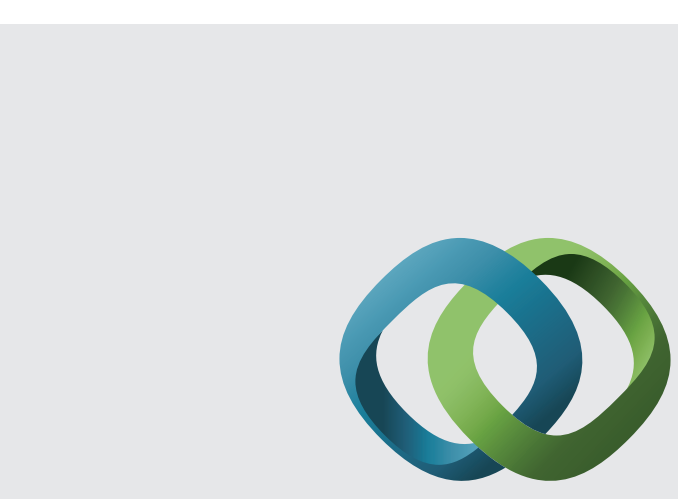

\section{Hindawi}

Submit your manuscripts at

http://www.hindawi.com
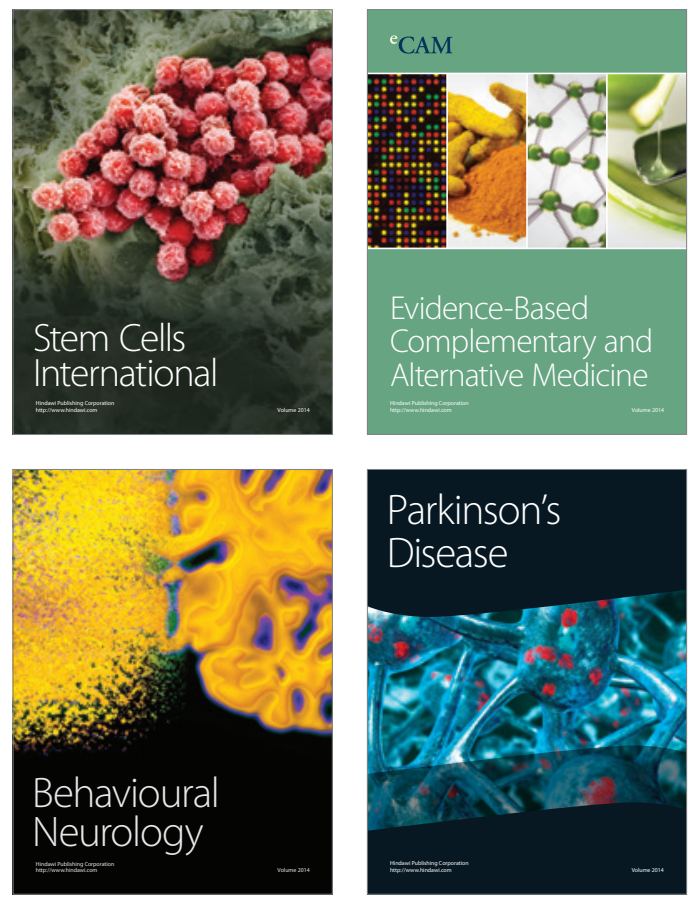
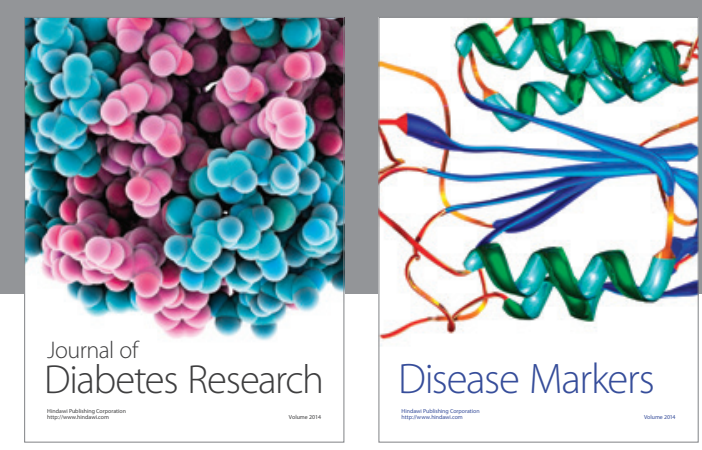

Disease Markers
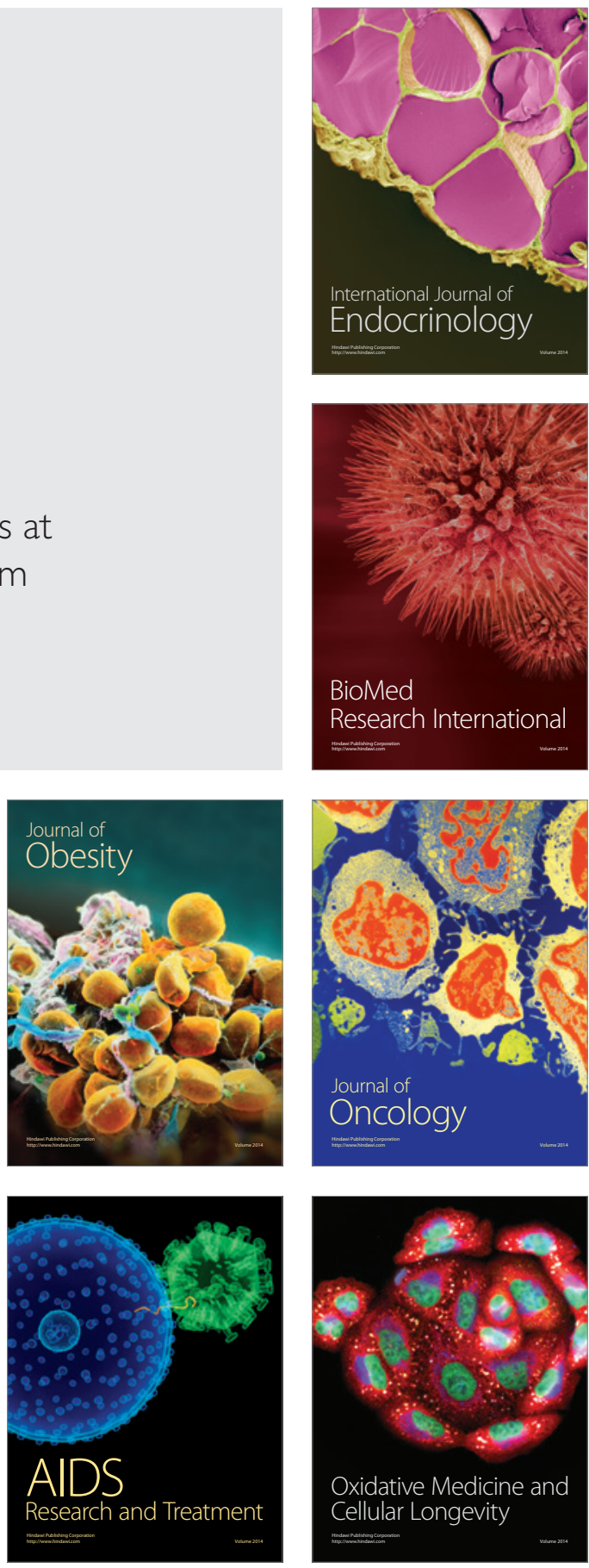